\title{
On the Relationship between Atmospheric Carbon Dioxide and Global Temperature
}

\author{
Alexander Ruzmaikin', Alexey Byalko² \\ ${ }^{1}$ Jet Propulsion Laboratory, California Institute of Technology, Pasadena, USA \\ ${ }^{2}$ Landau Institute of Theoretical Physics, Chernogolovka, Russia \\ Email: Alexander.Ruzmaikin@jpl.nasa.gov, alex@byalko.ru
}

Received 10 January 2015; accepted 15 May 2015; published 18 May 2015

Copyright (C) 2015 by authors and Scientific Research Publishing Inc.

This work is licensed under the Creative Commons Attribution International License (CC BY). http://creativecommons.org/licenses/by/4.0/

(c) (i) Open Access

\section{Abstract}

The study of dynamic relationships between the atmospheric carbon dioxide and the Earth's global temperature in the current changing climate supported the notion that the trend in the global temperature followed the trend in the atmospheric $\mathrm{CO}_{2}$ before the climate hiatus that started in the beginning of the 21st century. During the hiatus period, the heat trapped by the atmospheric $\mathrm{CO}_{2}$ is going mostly to the ocean. This conclusion is supported by comparison of the $\mathrm{CO}_{2}$ trend with the trend in the ocean heat content. The phase relationships between the $\mathrm{CO}_{2}$ and temperature are more complicated after the removal of the trends. The phase relationships are chaotic on time scales shorter than the annual time scale. During 1986-2008, the atmospheric $\mathrm{CO}_{2}$ changed in anti-phase with the global temperature. The phase relationship reversed in 1979 and after 2010. The atmospheric $\mathrm{CO}_{2}$ was in-phase with the global temperature on the El Niño time scale (2.3 - 7 years) except during very strong El Niño years in 1991-1999 when $\mathrm{CO}_{2}$ led the global temperature.

\section{Keywords}

Atmospheric Carbon Dioxide, Earth's Global Temperature, Phase Relationships

\section{Introduction}

Carbon dioxide $\left(\mathrm{CO}_{2}\right)$ is the major greenhouse gas that absorbs and re-emits the outgoing long wave radiation causing an increase of the Earth's heat content. The change in the Earth's surface global temperature $T$ is commonly considered to be driven by the increase of $\mathrm{CO}_{2}$. However, the situation is more complicated because the atmospheric concentration of $\mathrm{CO}_{2}$ does not follow the rate of its industrial emissions [1], see Figure 1. The re-evaluation of the current global temperature trend [2], indicates that in spite of the steadily growing trend in $\mathrm{CO}_{2}$ there has been no trend in the global temperature during the last 17 years [3]. 


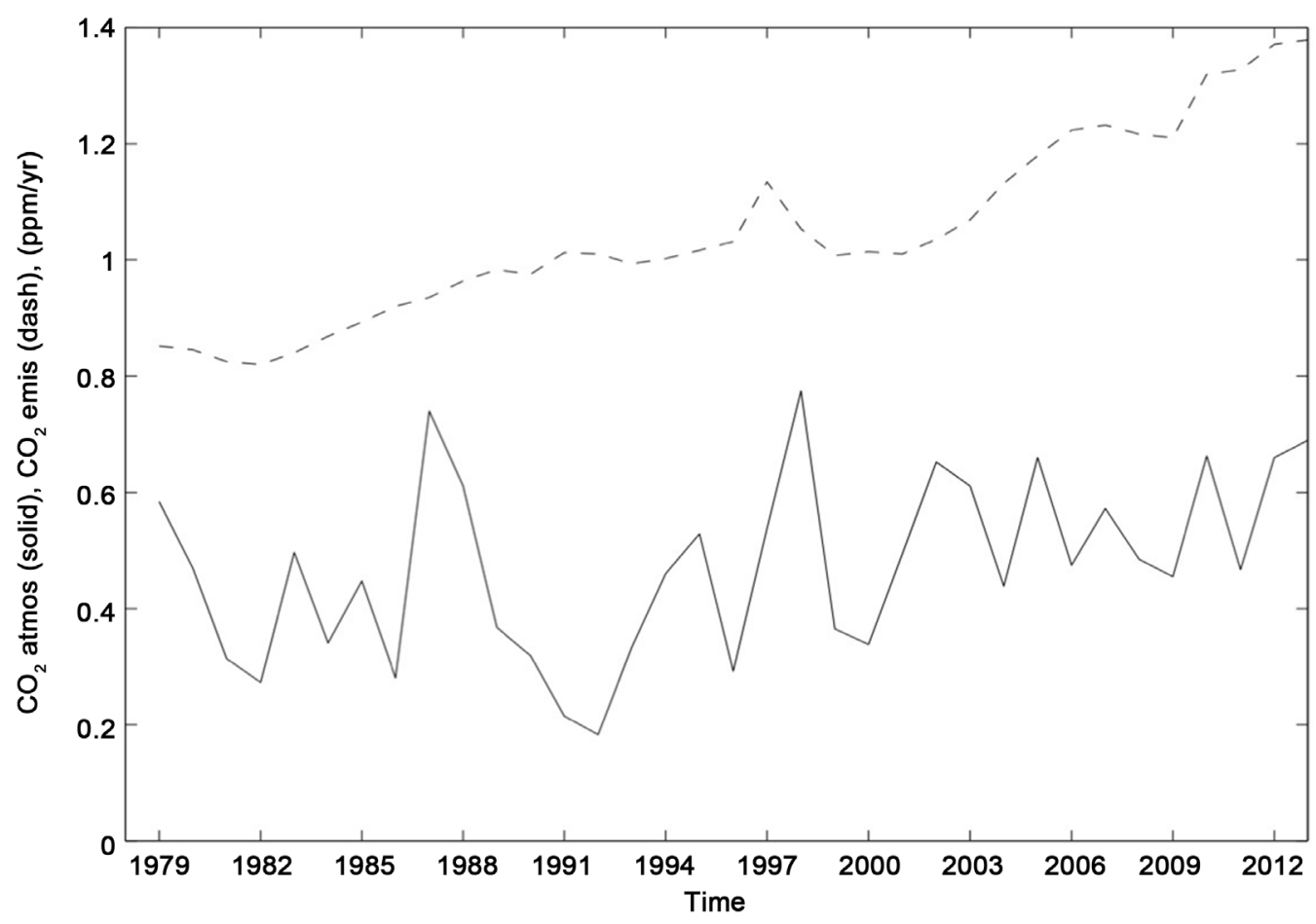

Figure 1. The atmospheric concentration (solid curve) and total emissions of $\mathrm{CO}_{2}$ (dashed curve), which includes emissions from fossil-fuel combustion, cement production, and change of land-use emissions [2]. The trend in the growth rate of the atmospheric $\mathrm{CO}_{2}(\mathrm{ppm} / \mathrm{yr} / \mathrm{yr})$ ends with the onset of the 21st century while the trend in the total $\mathrm{CO}_{2}$ emission rate increases.

Considering the critical role of $\mathrm{CO}_{2}$ and the Earth's temperature for climate change, it is imperative to investigate the relationship between them in more detail.

Paper [4] noting the inverse phase relationship between the trends of these two variables suggested that the temperature variations were not induced by changes in atmospheric $\mathrm{CO}_{2}$. However, it has been pointed out [5] that a differential method used in [4] removes the long-term trend in the $\mathrm{CO}_{2}$. The corrected analysis showed that the temperature trend followed the $\mathrm{CO}_{2}$ trend. A more general approach to the problem of phase relationship between the global temperature and all climate forcings was taken in [6] to test whether the global temperature follows the $\mathrm{CO}_{2}$ trends.

Less controversial were the analyses of the de-trended time series. References [4] and [7] analyzed the spectra of the $\mathrm{CO}_{2}$ measured at Mauna Loa Observatory (MLO) and the cross-correlations between the $\mathrm{CO}_{2}$ and global temperature and found that their Fourier spectra were similar to each other in the period range 2 - 10 years, and that the global temperature oscillations were leading the $\mathrm{CO}_{2}$ by about $7-11$ months. Three spectral lines (2.4 2.5, 3.6 - 3.8, and 8 - 9 years) were found to be close to spectral lines observed in the global atmospheric momentum oscillations and the length of day variability associated with it [8]-[10]. These spectral analyses indicated a physical connection between the global temperature (T), $\mathrm{CO}_{2}$ and El Niño-like variability.

Here we investigate the dynamical relationship between $T$ and $\mathrm{CO}_{2}$ using the global atmospheric $\mathrm{CO}_{2}$ and methods of spectral analyses that allow us to separate the long-term trend from natural oscillations and quantify their phase differences.

\section{The Global Atmospheric $\mathrm{CO}_{2}$ and Temperature Data}

To characterize the atmospheric $\mathrm{CO}_{2}$ over the Earth's globe we use the 2D distribution of zonally averaged atmospheric carbon dioxide mixing ratios from the NOAA ESRL Carbon Cycle Cooperative Global Air Sampling Network for 1979 to 2013 [11]. We use the monthly Earth's surface temperature from the global CRUTEM4 data set for the same time period developed by the Climatic Research Unit at University of East Anglia in conjunction with the Hadley Centre at the UK Met Office (http://www.cru.uea.ac.uk/cru/data/temperature/). 
Figure 2 shows the latitude-time distribution of the $\mathrm{CO}_{2}$. We see that as time progresses the atmospheric carbon dioxide tends to be more abundant in the Northern Hemisphere spreading around the globe within about a year. This diagram demonstrates not only an obvious fact that $\mathrm{CO}_{2}$ is mostly released in the Northern Hemisphere but also a less trivial process of the $\mathrm{CO}_{2}$ transport to the Southern Hemisphere and its timing. A similar distribution of the atmospheric carbon dioxide is found in the upper troposphere using satellite data [12]. The time series of the globally averaged atmospheric $\mathrm{CO}_{2}$ and the global temperature anomaly are shown in Figure 3 presenting the original data (panel a) and de-trended data (panel b). It is clear that the temperature trend in the 21st century does not follow the rise of $\mathrm{CO}_{2}$ although it had been close to the $\mathrm{CO}_{2}$ trend during the previous 30 years. However the Ocean Heat Content for the global ocean follows the globally smoothed (trend) in $\mathrm{CO}_{2}$ (panel c). The de-trended and annually smoothed data (panel b) indicate a more complicated behavior of the $\mathrm{CO}_{2}$ and global temperature.

\section{Phase Synchronization of Global Temperature and $\mathrm{CO}_{2}$}

It is not easy to extract clear and qualitative information about the phase relationship between $\mathrm{CO}_{2}$ and global temperature $T$ directly from their time series shown in Figure 3.

Modern dynamical system theories offer recurrence techniques allowing tracing the return of a variable to any of its values and comparing co-occurrences of such returns for two variables [13]. To investigate the relationship between the phases of our two variables $\left(C=\mathrm{CO}_{2}\right.$ and $\left.T\right)$ we apply the Recurrence-based Measure of

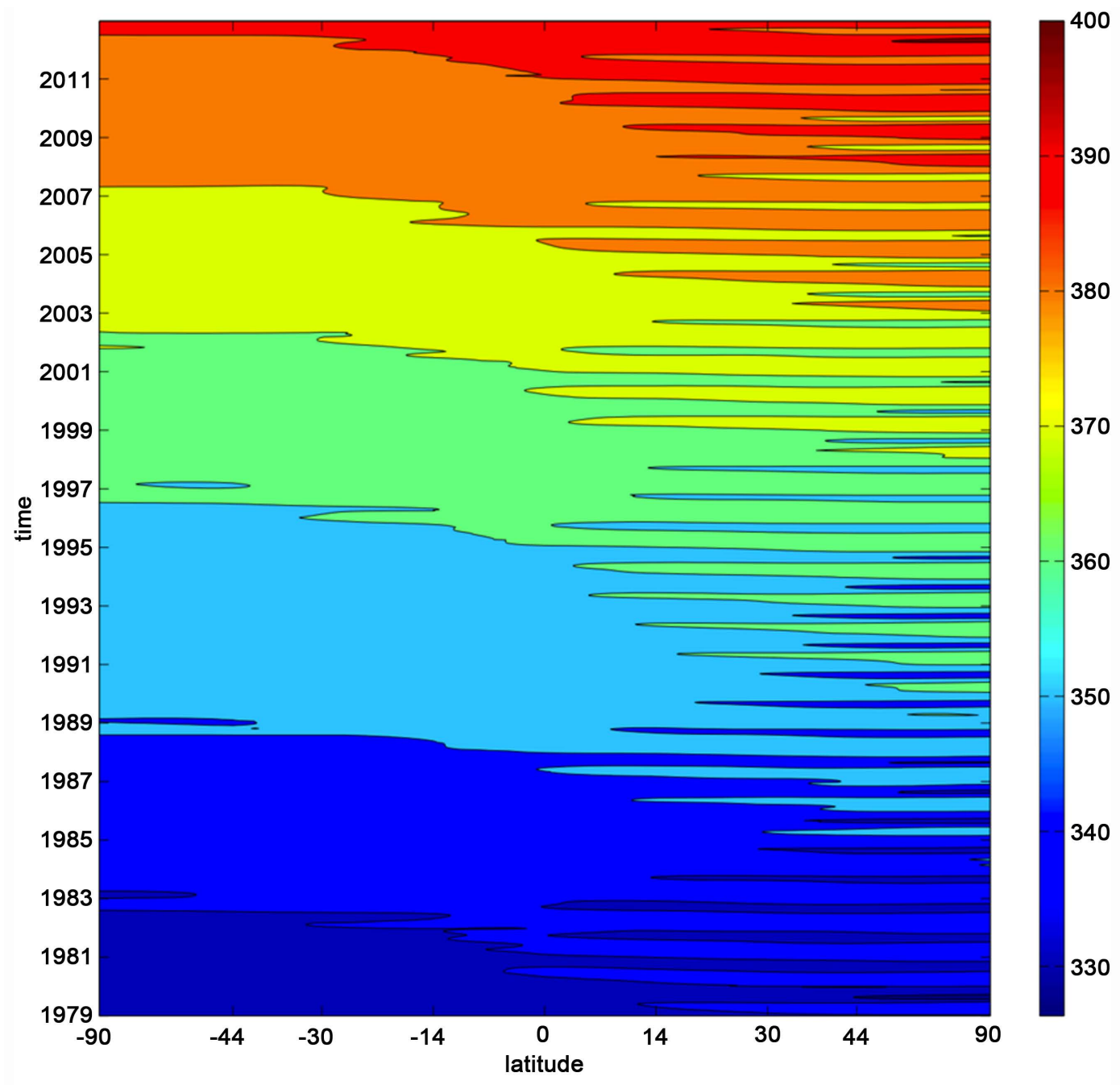

Figure 2. The latitude-time distribution of the $\mathrm{CO}_{2}$ at the Earth's surface. The color bar units are ppm. 

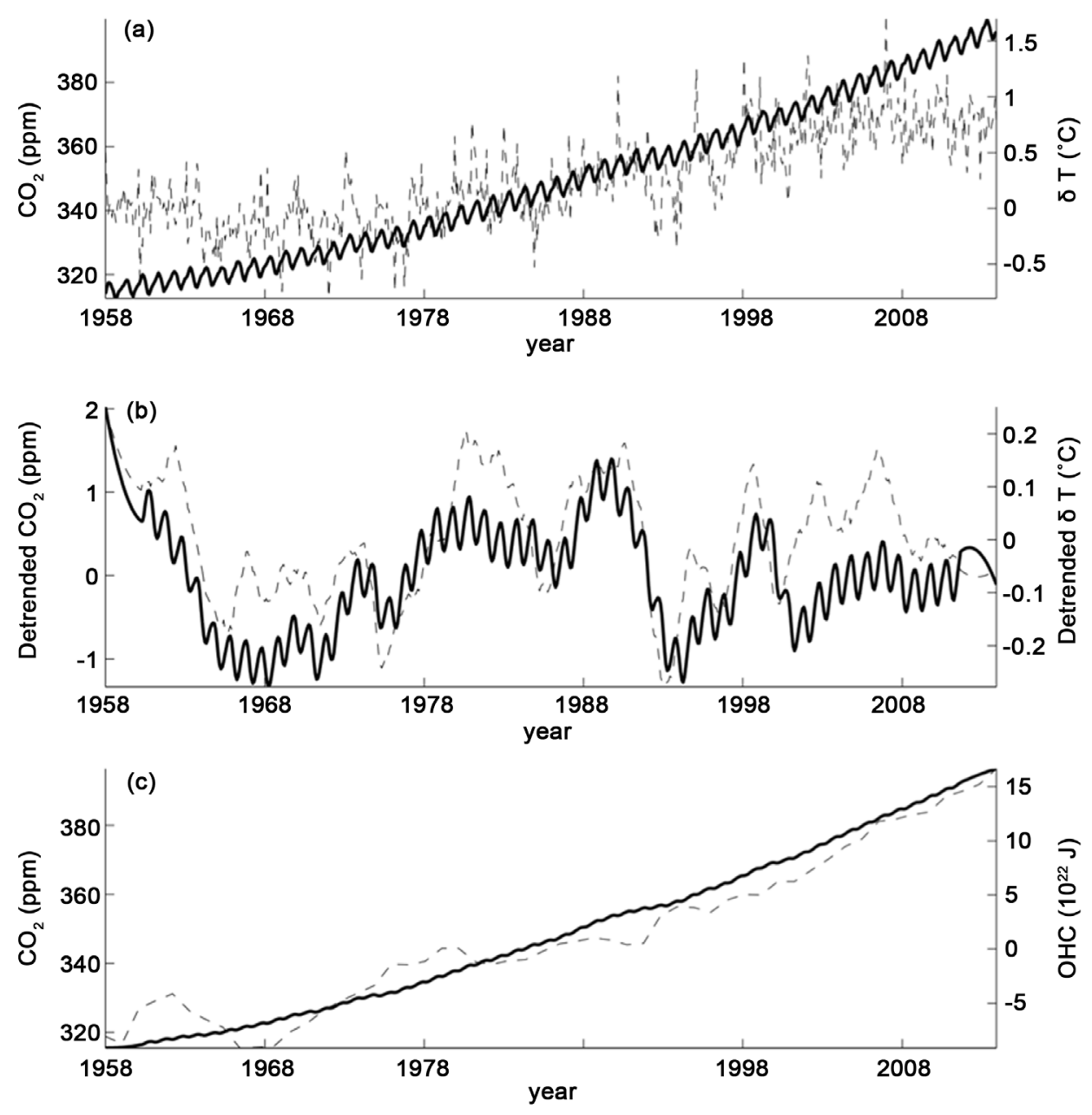

Figure 3. Monthly $\mathrm{CO}_{2}$ (solid) and global temperature anomaly (dash): (a) Original data; (b) Detrended data smoothed by 12 month filter for a better display; (c) Similarly smoothed the atmospheric $\mathrm{CO}_{2}$ concentration (solid) and the annually averaged ocean heat content in the top 2000 meters of the ocean (dash).

Dependence (RMD) suggested and used in [6]

$$
\operatorname{RMD}(\tau)=\log _{2}\left[\frac{1}{n-\tau} \sum_{i=1}^{n-\tau} \frac{P\left(C_{i}, T_{i}(\tau)\right)}{P\left(C_{i}\right) P\left(T_{i}(\tau)\right)}\right]
$$

where $\tau$ is the time shift between $C$ and $T, n$ is the length of the time series, $P\left(C_{i}\right)$ and $P\left(T_{i}\right)$ are probabilities that the values of $C$ and $T$ return to the point $C_{i}$ and $T_{i}$ correspondingly. The joint probability $P\left(C_{i}, T_{i}(\tau)\right)$ captures co-occurring of the returns to $C_{i}$ and $T_{i}$ at the same time instant $t=i$.

Figure 4 shows the Recurrence-based Measure of Dependence (RMD) for the original and de-trended data. We see that the global temperature follows and is strongly dependent on $\mathrm{CO}_{2}$ for all time lags in the original data (upper curve) but the two variables are almost independent when the trends are taken out (lower curve).

Now we investigate in detail the actual phase relationships between the de-trended $\mathrm{CO}_{2}$ and $T$ on all time scales by applying the wavelet coherence technique [14] allowing us to trace the phases of the two variables in time. Figure 5 shows that phase relationships on shorter time scales than annual time scale are chaotic, but there are statistically significant correlations on the annual time scale in 1986-2008. The directions of arrows indicate that $\mathrm{CO}_{2}$ is in anti-phase with the temperature changes in this period. But the directions of the arrows reversed in the beginning (in 1979) and the end (after 2010) of the data sets when $\mathrm{CO}_{2}$ and $T$ were varying in phase. On longer time scale there was a significant correlation with $\mathrm{CO}_{2}$ leading $T$ in 1994-1998, which we believe is 


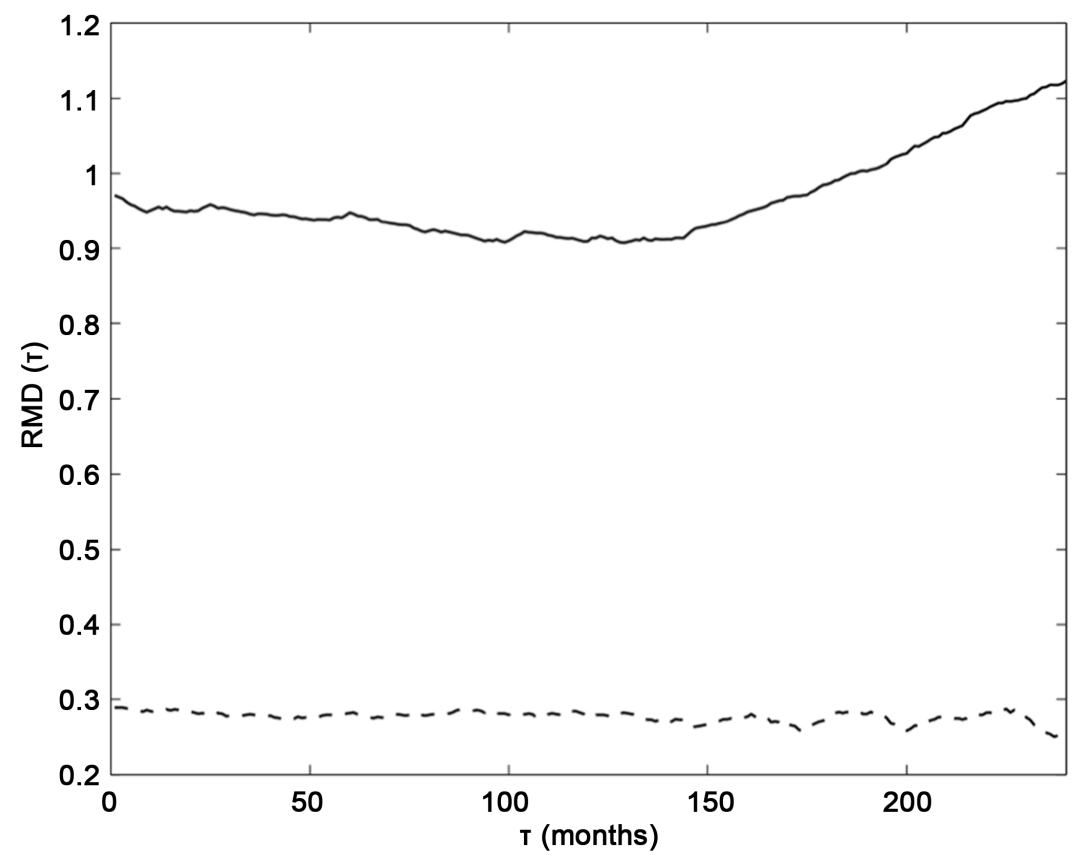

Figure 4. Recurrence-based measure of dependence for the original time series of $\mathrm{CO}_{2}$ and $T$ (upper curve) and for the de-trended time series (lower curve). The curves are calculated with the Matlab software that can be found at www.agnld.uni-potsdam.de/\%7Emarwan/toolbox.php.

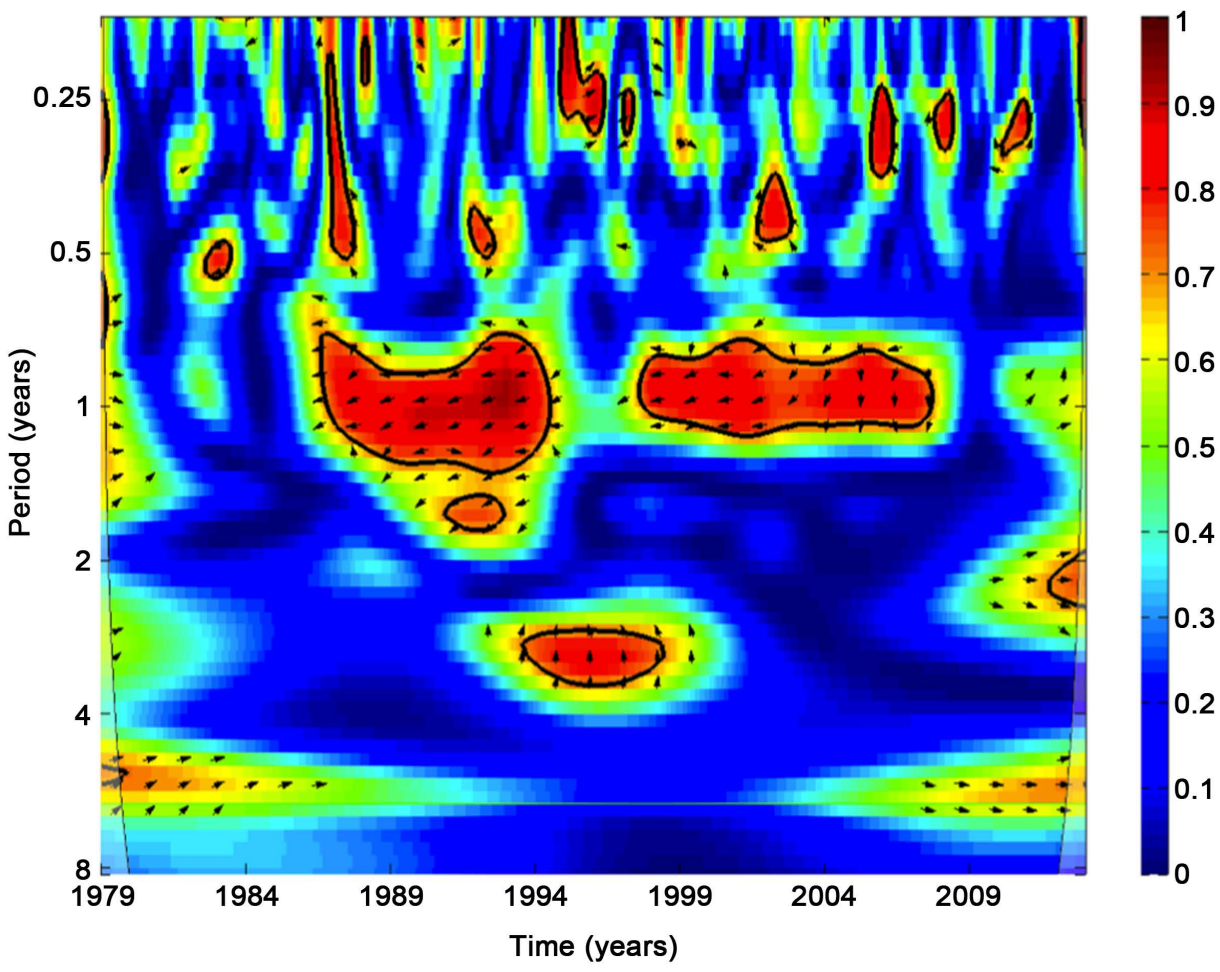

Figure 5. Wavelet coherence of the globally-averaged $\mathrm{CO}_{2}$ and global temperature. The thick black contours designate the 95\% significance level against red noise. The cone of influence where edge effects might distort the picture is shown by side lines. The phase relationships are indicated by arrows pointing right for the in-phase $\mathrm{CO}_{2}-T$ relationship, left for the anti-phase relationship, and straight up when $\mathrm{CO}_{2}$ is leading the temperature anomaly. 
related to the multiple relatively strong El Niño episodes occurred in that time period (http://www.esrl.noaa.gov/). The arrows at the time scale about 6 years clear indicate that the temperature was in phase with $\mathrm{CO}_{2}$ changes in the time period preceding and following the period of the strong El Niño episodes in 90s.

\section{Conclusions}

We confirm the previous findings [5] [6] that trend in the global Earth's temperature follows the trend in the atmospheric $\mathrm{CO}_{2}$ before the period of the climate hiatus. However, we show that the trends are not in phase during the hiatus when the heat trapped by the atmospheric $\mathrm{CO}_{2}$ goes mostly into the ocean. This is supported by comparison of the $\mathrm{CO}_{2}$ trend with the trend in the ocean heat content.

We find that after the removal of the trend there are more complex phase relationships between these variables. The phase relationships are chaotic on shorter time scales than the annual time scale. On the annual time scale, the atmospheric $\mathrm{CO}_{2}$ changed in anti-phase with the global temperature anomaly changes in the time period from 1986 to 2008 except for the end of it. This relationship was reversed in 1979 and after 2010 when $\mathrm{CO}_{2}$ and $T$ were changing in-phase. On the El Niño time scale (2.3 - 7 years), the atmospheric $\mathrm{CO}_{2}$ was in-phase with the global temperature changes except for the 1991-1999 time period, which included a very strong El Niño episodes, when the time scale was suddenly changed and $\mathrm{CO}_{2}$ led the global temperature.

\section{Acknowledgements}

The research described in this paper was carried out in part at the Jet Propulsion Laboratory, California Institute of Technology, under a contract with the National Aeronautics and Space Administration.

\section{References}

[1] Keeling, C.D., Whorf, T.P., Walen, M. and van der Plicht, J. (1995) Interannual Extremes in the Rate of Rise of Atmospheric Carbon Dioxide since 1980. Nature, 375, 666-670. http://dx.doi.org/10.1038/375666a0

[2] Le Quere, L., et al. (2014) Global Carbon Budget 2013. Earth System Science Data, 6, 235-263. http://dx.doi.org/10.5194/essd-6-235-2014

[3] (2014) Hiatus in Context. Nature Geoscience, 7, 154. www.natute.com/naturegeoscience

[4] Humlum, O., Solheim, J.-E. and Stordahl, K. (2013) The Phase Relation between Atmospheric Carbon Dioxide and Global Temperature. Global and Planetary Change, 100, 51-69. http://dx.doi.org/10.1016/j.gloplacha.2012.08.008

[5] Richardson, K. (2013) Comment on "The Phase Relation between Atmospheric Carbon Dioxide and Global Temperature” by Humlum, Stordahl and Solheim. Global and Planetary Change, 107, 226-228. http://dx.doi.org/10.1016/j.gloplacha.2013.03.011

[6] Goswami, B., Marwan, N., Feulner, G. and Kurths, J. (2013) How Do Global Temperature Drivers Influence Each Other? European Physical Journal Special Topics, 222, 861-873. http://dx.doi.org/10.1140/epjst/e2013-01889-8

[7] Byalko, A.V. (2013) Spectra of Climate Perturbations. Priroda, 9, 17-26.

[8] Dickey, J.O., Marcus, S.L. and de Viron, O. (2003) Coherent Interannual and Decadal Variations in the AtmosphereOcean System. Geophysical Research Letters, 30, 1573. http://dx.doi.org/10.1029/2002GL016763

[9] Sidorenkov, N.S. (2009) The Interaction between Earth's Rotation and Geophysical Processes. Wiley-VCH Verlag GmbH \& Co. KGaA, Weinheim. http://dx.doi.org/10.1002/9783527627721

[10] Abarca-del-Rio, R., Gambis, D. and Salstein, D. (2012) Intrdecadial Oscillations in Atmospheric Angular Momentum Variations. Journal of Geodetic Science, 2, 42-52. http://dx.doi.org/10.2478/v10156-011-0025-8

[11] Dlugokency, E.J., Masarie, K.A., Lang, P.M. and Tans, P.P. (2013) NOAA Greenhouse Gas Reference from Atmospheric Carbon Dioxide.

[12] Ruzmaikin, A., Aumann, H.H. and Pagano, T.S. (2012) Patterns of $\mathrm{CO}_{2}$ Variability from Global Satellite Data. Journal of Climate, 25, 6383-6393. http://dx.doi.org/10.1175/JCLI-D-11-00223.1

[13] Marwan, N., Romano, M.C., Thiel, M. and Kurths, J. (2007) Recurrence Plots for the Analysis of Complex Systems. Physics Reports, 438, 237-329. http://dx.doi.org/10.1016/j.physrep.2006.11.001

[14] Grinsted, A., Moore, J.C. and Jevrejeva, S. (2004) Application of the Cross Wavelet Transform and Wavelet Coherence to Geophysical Time Series. Nonlinear Processes in Geophysics, 11, 561-566. http://dx.doi.org/10.5194/npg-11-561-2004 